\title{
PARQUES E RESERVAS FLORESTAIS DO MUNICÍPIO DE MARINGÁ/PR
}

\section{Paulo Roberto de Sousa ${ }^{1}$}

\section{Carmino Hayashi ${ }^{2}$}

RESUMO: O crescimento populacional em áreas urbanas teve um crescimento bastante acentuado com o advento do sistema capitalista, após a revolução industrial. A falta de planejamento urbano levou a diversos problemas ambientais, principalmente pela devastação de áreas verdes, tais como as reservas florestais. A cidade de Maringá, não foge a regra dos grandes centros urbanos, pois se compararmos as áreas florestais de algumas décadas atrás com a atual, constataremos uma redução drástica das florestas originais. Conhecida como uma das melhores cidades arborizadas do país, entretanto apresenta uma condição bastante atípica, ou seja, uma arborização exuberante em toda extensão do perímetro urbano e pouquíssima vegetação fora deste perímetro. As três maiores reservas florestais da cidade, totalizam 143 ha, o que representa 0,3\% da superfície total do município, que possui ainda várias outras reservas florestais de pequeno porte. Este trabalho objetivou efetuar um diagnóstico dos parques e reservas florestais da cidade, através do histórico de sua criação, levantamento de seu acervo, além de tecer algumas considerações sobre o assunto. Além do Parque do Ingá, Parque dos Pioneiros e Horto Florestal, analisaram-se diversas outras áreas criadas oficialmente. Projetada para uma perspectiva inicial de 50 anos, o município ultrapassou em muito esta previsão inicial, acarretando problemas urbanísticos e ambientais. Hoje com sérios problemas em suas reservas florestais, a cidade precisa repensar o seu desenvolvimento urbano e rural de forma integrada e regional, caso contrário pagará um pesado tributo em termos de sustentabilidade ambiental.

Palavras-chave: Áreas de proteção ambiental. Parques e reservas florestais. Vegetação

\footnotetext{
${ }^{1}$ Geógrafo - Especialização em Ecologia Aplicada - Universidade Estadual de Maringá - Maringá/PR

${ }^{2}$ PVNS/CAPES/UFTM - Universidade Federal do Triângulo Mineiro - Uberaba/MG Autor para correspondência: e-mail: hayashi@terra.com.br
} 


\section{INTRODUÇÃO}

Algumas estimativas indicam que o Brasil conta com mais de $73 \%$ de sua população nas zonas urbanas, enquanto que na década de 50 este percentual não atingia $50 \%$ de acordo com Moraes (1996). Este grande avanço das áreas urbanas ocorreu a partir da implantação do sistema capitalista, principalmente após a Revolução Industrial, em cujo processo o meio ambiente foi submetido a uma contínua devastação, colocando em risco o equilíbrio do planeta e afetando a vida de toda a humanidade. Houve um grande incremento dos problemas ambientais urbanos principalmente em decorrência da expansão das atividades econômicas concentradas nas cidades, entre os quais se destacam a poluição sonora, visual chuvas ácidas, inversão térmica, ilha de calor e depósito de lixo (LUCCI, 1997); ao mesmo tempo em que o solo urbano sofreu grandes interferências como a impermeabilização pela pavimentação de ruas e construções utilizando-se materiais como concreto, vidro, ferro, asfalto e cerâmica, o que gerou uma redução drástica da cobertura vegetal.

Através da Revolução Industrial, a cidade passou a ser o centro da economia e a base do desenvolvimento capitalista, pois em decorrência do crescimento populacional e da intensificação do processo de urbanização; a interferência humana nos meios naturais passou a ocorrer num ritmo acelerado. Isto significa que o aumento populacional está diretamente vinculado ao aumento no consumo dos recursos naturais, gerado pelas necessidades básicas como moradias, mais fonte de trabalho, centros industriais e comerciais e vias de transportes. Estas necessidades, associadas à falta de um eficiente planejamento urbano, provocaram grandes impactos ambientais, principalmente relacionadas à devastação de áreas verdes, tais como reservas florestais. Neste sentido podemos afirmar que dentre as várias formas de amenizar os problemas ambientais, a manutenção e conservação de reservas florestais, assim como a criação de áreas verdes através de reflorestamentos; é de fundamental importância para o meio cosmopolita, o que pode ser verificado conforme Branco (1992), Tudini (2001) e Souza et. al. (2006).

O município e a cidade de Maringá/PR, objeto deste estudo, considerada uma cidade projetada e com altíssima qualidade ambiental, não foge a regra de outros grandes centros urbanos, pois se compararmos as áreas florestais de algumas décadas atrás com a atual, constataremos uma redução significativa das áreas verdes. Geralmente, estes 
agravantes ocorrem basicamente provocadas pela inexorável especulação imobiliária nos grandes centros urbanos e a construção de grandes obras impactantes, associadas à falta de planejamento sustentável; onde encontramos as instalações de indústrias, conjuntos habitacionais e o aumento da frota de veículos. Da mesma forma, a abertura de avenidas, ruas e estradas; embora contribuam para o progresso da cidade, por outro lado, contribuem para impactar e degradar mais ainda o meio urbano em termos ambientais; daí que o incentivo para a criação de parques e reservas florestais representa um dos principais elementos na estratégia para conservação do meio ambiente, principalmente em centros urbanos. Neste processo de expansão de ambientes urbanos, a qualidade das questões ambientais e sociais tem sido relegada ao segundo plano (LOBATO, 2005).

A escassez de vegetação nativa é uma constante não apenas em Maringá, como também em todo Estado do Paraná e podemos dizer até de todo o Brasil e do mundo. O processo de ocupação do Estado ocorreu num ritmo muito acelerado onde a cobertura florestal original de $83 \%$ foi reduzida drasticamente para um nível de $24 \%$ em 1968, 11\% em 1974 e atualmente 4\%. Referindo-se a região de Maringá, que é uma região essencialmente agrícola, a redução da vegetação nativa foi severamente reduzida a uma cobertura florestal média de aproximadamente 0,5\% (MILANO, 1988). Conhecida como uma das cidades mais arborizadas do país, Maringá apresenta uma condição bastante atípica, ou seja, conta com uma arborização exuberante em toda extensão do perímetro urbano, e a inexistência, praticamente, da vegetação fora deste perímetro, em função da ocupação de cultivos agrícolas. No perímetro urbano obtém um bom índice de 20,6 $\mathrm{m}^{2}$ de área verde pública/habitante, onde $14 \mathrm{~m}^{2}$ estão representadas pela arborização de ruas e o restante pelas áreas verdes existentes na cidade, o destaca a condição privilegiada dos habitantes da área urbana, que totalizam $96 \%$ de toda a população do Município (Prefeitura Municipal de Maringá, 1993a).

Na cidade de Maringá, as três grandes reservas florestais da cidade pertencem atualmente a Prefeitura Municipal de Maringá (Parque do Ingá e Bosque II - Parque dos Pioneiros) e a Cia Melhoramentos Norte do Paraná (Horto Florestal); totalizando 143 ha, o que representa 0,3\% da superfície total do Município (Prefeitura Municipal de Maringá / SEPLAN, 1996). O Município possui ainda várias outras reservas florestais de pequeno porte espalhados pelo perímetro urbano, os quais também contribuem para melhorar a qualidade de vida da cidade; o que tem levado o poder público municipal a utilizar-se 
desse discurso as ações na utilização da boa imagem ambiental como forma de divulgação da "Cidade Verde", conforme Paula (1998).

Desde o início da colonização de Maringá, a grande preocupação da Cia Melhoramentos Norte do Paraná era com relação à arborização da mesma e preservação de reservas florestais (GARCIA, 2006), tais como Horto Florestal, Bosque II, Parque do Ingá, e um planejamento de pequenas reservas espalhadas pela periferia da cidade, reservas estas que são consideradas hoje como os "pulmões da cidade". Esta preocupação levou a Cia Melhoramentos Norte do Paraná, a contratar os serviços do paisagista Dr. Luiz Teixeira Mendes, que aqui permaneceu de 1949 a 1954; ao mesmo tempo em que também contratava em 1952, o agrônomo Dr. Aníbal Bianchini da Rocha (Prefeitura Municipal de Maringá, 1985).

Os conceitos básicos para definição de reservas florestais, reservas biológicas, áreas de proteção ambiental, parques nacionais, áreas naturais tombadas e estações ecológicas, utilizadas neste trabalho foram embasadas em Youssel et al. (1997).

Portanto os principais objetivos deste trabalho seria destacar a importância da vegetação para o meio urbano, caracterizando e evidenciando a situação atual dos parques e reservas florestais da cidade de Maringá

\section{PARQUES DO MUNCÍPIO DE MARINGÁ - ESTADO DO PARANÁ}

\section{Parque do ingá}

Por volta da década de 60 houve uma queimada acidental que devastou uma enorme área na reserva florestal onde mais tarde se tornaria o Bosque I, atualmente Parque do Ingá. Esta queimada ocasionou uma clareira no interior da mata, onde descobriram uma pequena fonte de água, formando um pequeno lago denominado "lago das lavadeiras", em função de ser utilizado pelas mulheres para a lavagem de roupas; além disso, o barro que ali se formava era utilizado pelas olarias da cidade. A Companhia Melhoramentos Norte do Paraná que iniciou a colonização da região de Maringá por volta de 1943, obedecendo à legislação de proteção de mananciais em vigente na época, manteve dois parques então denominados Bosque I (Parque do Ingá) e Bosque II. O autor 
do projeto urbanístico de Maringá, Jorge Macedo Vieira, estabeleceu a permanência destas áreas verdes, procurando salvaguardar o tipo de vegetação existente na região. Em 1969 com o crescimento da cidade e a consequente demanda por áreas de lazer, o Bosque I foi urbanizado, sendo inaugurado e aberto à visitação pública em 10/10/1971, com o nome de Bosque Dr. Etelvino Bueno de Oliveira. Através da Lei Municipal $n^{\circ}$ 880/71, foi oficialmente denominado de Parque do Ingá, em função da abundância dos pés de Ingá. Posteriormente foi declarado pela Câmara Municipal de Maringá como área de preservação permanente, o que foi confirmado em 1990, através da Lei Orgânica do Município de Maringá (1997), em seu Artigo 174 de 17/04/90. O Parque do Ingá é de propriedade da Prefeitura Municipal de Maringá desde 1986 (Registro $n^{0}$ 2.796), localizando-se na região central do perímetro urbano, com uma superfície de $474.300 \mathrm{~m}^{2}$.

Em termos de características gerais de vegetação, o Parque do Ingá correspondia a uma área de domínio da Floresta Estacional Semidecidual, não apresentando hoje as características originais, tendo em vista a grande devastação ocorrida e a introdução de espécies não-naturais da região, apresentando hoje uma vegetação característica de uma floresta primária alterada. Num levantamento realizado na área, foram encontradas 44 espécies, conforme relação da composição florística do Parque do Ingá, segundo a Prefeitura Municipal de Maringá (1994b). Também foram encontradas espécies típicas da Floresta Estacional Semidecidual, como por exemplo, o alecrim, gurucaia, roseira, capixingui e jacaratiá, tapiá, cedro, canjarana e monjoleiro, o que confirma que a floresta presente no Parque do Ingá representa um remanescente alterado da Floresta Estacional Semidecidual.

Em termos hidrográficos, no Parque do Ingá possui várias nascentes do córrego Moscado, pertencente à microbacia do Ribeirão Pinguim, Bacia Hidrográfica do Rio Ivaí; que no ano de 1970 foi represado, estabelecendo-se a partir de então um grande lago na parte central do parque.

Anteriormente ao processo de colonização, certamente a região do Parque do Ingá era de uma grande riqueza faunística, que sofreu drásticas alterações com a intensificação e exploração madeireira e a rápida expansão urbana. Porém ainda hoje, mesmo numericamente reduzidas restam no interior do Parque do Ingá, espécies como tatu-galinha, tatu-peludo, tatu-mulita, graxaim, mão-pelada, gambá, preás, micro roedores, "morcegões", que são mamíferos de pequeno porte e que são mais resistentes às 
intervenções antrópicas. No tocante a avifauna, existem poucas espécies remanescentes, talvez devido a pouca diversidade vegetais fornecedoras de itens alimentares. Cumpre lembrar que na região leste do lago, foi construído em 1971 um pequeno zoológico, para abrigar alguns poucos animais, que foram incrementados com as apreensões feitas na região, levando o município a investir na ampliação destes recintos dentro das especificações e normas técnicas exigidas para cada espécie.

Afora estas características da flora e fauna, o Parque sofreu diversas intervenções, como a construção do Jardim Japonês que fica localizado à oeste do lago, foi construído em 1978, quando da visita do então príncipe Akihito e da princesa Michiko à Maringá; assim como uma Gruta nas proximidades do Jardim Japonês, construída em 1971, para receber a imagem de Nossa Senhora Aparecida. Entre outras inserções ao longo do tempo, devemos citar a colocação da uma locomotiva antiga, logo na entrada do portão principal, a primeira a chegar a Maringá em 31/01/1954. O Parque abriga também a sede da ADEAM: Associação de Defesa e Educação Ambiental de Maringá, inaugurada em 31/05/1988, assim como um Posto da Polícia Florestal. Em termos de áreas de lazer o Parque possui internamente pistas pavimentadas para caminhadas, assim como externamente em toda a sua volta, playground entre as trilhas, quadra de bocha em madeira, ancoradouros e "pedalinhos" para passeios no lago, lanchonete e sanitários públicos.

Não restam dúvidas que a vegetação do Parque do Ingá, embora extremamente impactadas antropicamente, contribui positivamente para a qualidade de vida da população, principalmente no tocante a importância da vegetação no controle de vários tipos de poluição (minimização). Justamente por ser referencialmente um grande ponto turístico e recreativo, são necessários cuidados especiais por parte do poder público no tocante a melhoria e manutenção do mesmo, tendo em vista a permanência de recursos florísticos e faunísticos em seu interior, principalmente em relação aos processos de erosão existentes. Estes cuidados extrapolam os limites do parque e somente serão resolvidos mediante uma tomada de posição integrada aos sistemas de escoamentos de águas pluviais no entorno do parque e da cidade (áreas de contribuição).

\section{Bosque II - Parque Florestal dos Pioneiros}


O Bosque II (Parque Florestal dos Pioneiros) localiza-se no perímetro urbano da cidade, possuindo uma área de 59 ha, compreendido entre as Zonas 2, 4 e 20; tendo sido preservado inicialmente por ocasião do período de colonização do município com o intuito de preservar a vegetação nativa ali existente, além de garantir as nascentes naturais, em obediência à legislação de proteção ambiental vigente, permanecendo até hoje na forma de áreas de preservação permanente.

Em 1968 a Câmara Municipal de Maringá, através da Lei 636/68, autorizou o Poder Executivo a implantar no Bosque um jardim zoobotânico que chegou a ser projetado, mas não implantado. Em 1982 a área do Bosque foi declarada pela Câmara Municipal como área de preservação permanente através da Lei 1.556/82 e, um ano após denominada de "Parque Florestal dos Pioneiros", pela Lei 1.556/82 que autorizava o Poder Executivo Municipal a proceder a recuperação ambiental e urbanização permitindo a construção de um complexo arquitetônico denominado Centro Cultural; além de permitir também a construção de um complexo hoteleiro. Entretanto, inúmeras manifestações foram contrárias a construção deste complexo, destacando os prejuízos ambientais que esta obra acarretaria e também pela sua ilegalidade, uma vez que esta área havia sido declarada de preservação permanente, assegurada pelo Artigo $2^{\circ}$ da Lei Federal $n^{\circ}$ 4.771/65.

A vegetação deste Bosque é constituída por uma formação vegetal secundária, originada pelas inúmeras intervenções do homem sobre a vegetação original. De acordo com as características da vegetação regional esta fase pode ser denominada de capoeirão, caracterizada como uma transição de fases iniciais (capoeira), dominada por espécies de crescimento rápido e de vida curta. Algumas partes do bosque como a que está localizada a leste, constitui um remanescente da floresta original, embora de dimensões reduzidas, com características florísticas e estruturas tratada como Floresta Primária Alterada; cuja composição florística mostra-se muito semelhante a do Parque do Ingá, em suas fases originais. O capoeirão é constituído por uma população arbórea diversificada cuja altura varia de 10 a 14 metros, de onde emergem espaçadamente espécies remanescentes da floresta original, tais como a peroba, canafístula, alecrim, marfim, capixingui, cajarana, guatambu, piúna, monjoleiro e tapia; sendo comuns ainda o cedro, canelinha, feijão-cru, louro e a paineira (Prefeitura Municipal de Maringá, 1993a).

Hidrograficamente existe o Córrego Cleópatra, cuja nascente está localizada 
neste Bosque, também pertencente à microbacia do Ribeirão Pinguim, Bacia Hidrográfica do Rio Ivaí; e que tem sofrido durante todos estes anos um processo de assoreamento provocado por despejos pluviais, além de resíduos domésticos e industriais.

Em termos faunísticos, o ambiente do Bosque II é apropriado para espécies que estão adaptadas para viver nas bordas de formações vegetais, tais como pássaros, pequenos roedores, espécies como o gambá de orelha branca, ouriço cacheiro, macacoprego, lagartos, sagui e uma variada avifauna (Prefeitura Municipal de Maringá, 1993a), muito semelhante à fauna do Parque do Ingá.

No ano de 1976 o Bosque II sofreu um grande desmate transversalmente para a efetivação da construção da Via Perimetral Sul Juscelino Kubitschek, ligando a zona leste ao oeste da cidade, não tendo sido registrado oficialmente nenhuma manifestação contrária ao referido desmate, naquela ocasião.

Mais recentemente, no final da década de 90 , foi construído na zona norte do bosque uma edificação, com recursos do governo estadual, denominada Usina do Conhecimento; objetivando ministrar cursos e treinamentos em várias áreas do conhecimento, embora neste caso houvesse protestos e manifestações na tentativa de embargar a referida construção alegando agressão ao meio ambiente.

Como o Bosque II localiza-se em um fundo de vale onde nasce o Córrego Cleópatra, a declividade do terreno e a existência de um sistema de captação de água das galerias pluviais que canaliza diretamente para o bosque; resultam em fatores que vão provocar graves processos de erosão, resultando na formação de extensas voçorocas. Convém lembrar também que na década de 70 , houve um grande fator de agravamento da erosão no Bosque devido a implantação de uma pista de "motocross", com um grande desmatamento e prejuízos à vegetação e topografia local; construção esta que foi rapidamente desativada em função da degradação ambiental que provocou.

Estes ambientes e vegetações mesmo sob os fortes impactos provocados pela urbanização, e altamente modificados, representam um dos últimos remanescentes da vegetação da região noroeste do Paraná. Mesmo não estando aberto à visitação pública, o Bosque atrai diariamente para o seu entorno muitas pessoas, tanto para caminhada em suas calçadas externas, como também em função da existência de bandos de macacospregos, que se tornaram um atrativo para a população. Tecnicamente, o Bosque II poderia servir como uma importante fonte de estudos envolvendo estudos da flora e fauna 
regional, porém faz-se necessário um competente plano de manejo, reorganizando o local com espécies nativas, e adotando um rígido controle da erosão; associadas às tomadas de medidas acompanhadas por técnicos qualificados.

\section{Horto Florestal "Dr. Luiz Teixeira Mendes"}

Com o intuito de buscar novas terras para o plantio de café, fazendeiros paulistas e mineiros iniciaram a colonização do Norte do Paraná, conhecido pelas suas terras férteis, quando a colonizadora Britânica Paraná Plantations Company, através de sua subsidiária, Companhia de Terras Norte do Paraná, adquiriu do Governo do Estado e alguns posseiros uma gleba de 515.000 alqueires que veio a se constituir no Norte Novo. Posteriormente, um grupo de brasileiros adquiriu dos ingleses a Companhia de Terras, passando a ser denominada Companhia Melhoramentos Norte do Paraná (Norte Novíssimo), conforme consta no SEPLAN/Prefeitura Municipal de Maringá (1996).

Portanto, como a cidade foi planejada e construída sob a ótica da Companhia Melhoramentos, esta era detentora da maioria dos lotes e terrenos na cidade de Maringá, entre os quais a área do Horto Florestal, desde a colonização da região. A criação dessa área decorreu da existência de uma represa onde nasce o Córrego Borba Gato, e um ajardinamento ao redor da mesma; cujo idealizador foi o agrônomo Dr. Luiz Teixeira Mendes, que hoje lhe empresta o seu nome.

O Horto Florestal localiza-se na porção sudoeste do Município de Maringá, possuindo uma área de $368.300 .00 \mathrm{~m}^{2}$, situando-se na Avenida Dr. Luiz Teixeira Mendes (Perimetral Sul) a cerca de cinco quilômetros do centro de Maringá (Prefeitura Municipal de Maringá, 1985b).

Hoje o Horto Florestal "Dr. Luiz Teixeira Mendes", constitui-se num dos últimos remanescentes regionais da vegetação típica da Floresta Estacional Semidecidual (HATSCHBACH \& ZILTER, 1995), e inicialmente foi também muito utilizado para produção de mudas de espécies nativas que hoje proliferam na arborização de Maringá e região.

Em 1994 o Poder Executivo Municipal tornou a área de relevante interesse ecológico, através do Decreto 203/94, sendo que atualmente essa área é aberta a visitação pública, sendo utilizado como área recreativa e para fins de pesquisas ambientais, entretanto, como se trata de uma área particular, não recebe investimentos de 
ordem pública para efetuar melhorias, e tampouco o reconhecimento como área de preservação natural.

Inicialmente a área do Horto Florestal era recoberta pelo tipo florestal semidecidual, Floresta Estacional Semidecidual, com características semelhantes à Floresta Atlântica, de composição florística diversificada; no entanto, posteriormente diversas espécies não nativas foram ali introduzidas. Podemos encontrar nesta área uma floresta primária alterada, com árvores de grande porte como: canelão, tapiá, monjoleiro, capixingui, gurucaia, paineira, cedro, roseira, canjerana, tamanqueiro, jacaratiá, ingá, canelinha e araticum-do-mato (Companhia Melhoramentos Norte do Paraná, 1977).

Por outro lado, algumas áreas do Horto Florestal encontram-se bastante degradadas, recobertas por cipós e taquaras, impedindo a regeneração da vegetação original; entretanto são áreas que podem ser tecnicamente recuperadas e controladas. Como é muito próxima em termos de biomas, esta composição florística é muito semelhante a do Parque do Ingá e do Parque dos Pioneiros, devido as suas mesmas origens naturais.

Com o advento da colonização, após a década de 40 ocorreram várias alterações nas formações vegetais que acabaram por prejudicar a composição faunística, principalmente a avifauna devido a diminuição de planta frutíferas nativas. Algumas espécies que conseguiram se adaptar e puderam resistir às alterações ambientais se mantiveram, tais como o urubu campeiro, gavião-carijó, saracura-do-mato, quero-quero, anu-preto, anu-branco, beija-flor, pica-pau-do-campo, joão-de-barro, bem-te-vi, andorinha, coruja, sabiá-laranjeira, tico-tico, canário terra, tiziu, coleirinha, sanhaço, pintassilgo (Companhia Melhoramentos Norte do Paraná, 1977). Dentre a fauna de mamíferos ainda encontrados no Horto Florestal destacam-se o macaco-prego, que vivem em bandos, soltos pelas árvores e tem se tornado até um problema pelos seus comportamentos, embora sejam atrações para os visitantes. Outros representantes da fauna local nativa é o quati, que tem seu habitat no interior da mata e retiram seus alimentos das árvores; o tatugalinha, o tatu-peludo, o tatu-mulita, a cutia; entre outros que também resistiram às grandes intervenções antrópicas que alteraram o equilíbrio ambiental do Horto Florestal.

\section{Outras Reservas Florestais}


Além das três principais reservas florestais, situadas em áreas urbanizadas praticamente na região central da cidade, Maringá apresenta dentro de seus limites urbanos mais afastados diversas pequenas reservas, remanescente da vegetação nativa, que se encontram regulamentadas ou em áreas e fases de regulamentação, conforme dados constantes no PMM/SEPLAN (1996):

a) Parque Municipal Borba Gato, instituído pelo Decreto Lei 504/94, localizada no Anel Viário, Rua Primavera, com uma área de 7.650,00 m².

b) Parque Florestal Municipal da Gurucaia, com uma área de 192.000,00 m², localizada na Gleba Ribeirão Pinguim.

c) Parque Florestal Municipal das Perobas, Decreto Lei que a regulamentou 419/95, localizada na PR-317 saída para Campo Mourão, com uma área de 263.348,74 m².

d) Parque Ecológico Municipal do Guaiapo, localizada na Avenida Sofhia Rasgulaeff esquina com a Rua Itapuã, com 16.205,48 $\mathrm{m}^{2}$.

e) Parque do Sabia, localizado na Avenida Prefeito Sincler Sambatti, Decreto Lei 204/98 com uma área de $88.165,41 \mathrm{~m}^{2}$.

f) Parque do Cinquentenário, localizado a Rua Palmital - Jardim Imperial, com 118.125,03 $\mathrm{m}^{2}$, instituída pelo Decreto Lei 674/97.

g) Parque da Rua Teodoro Negri, localizado no Conjunto Thaís - Zona 19, com $49.000,00 \mathrm{~m}^{2}$.

h) Parque Florestal Municipal das Palmeiras, instituída pelo Decreto Lei 504/94, localizada no Jardim Vitória, com uma área de $61.134,48 \mathrm{~m}^{2}$. Neste parque foi previsto programas de educação ambiental, instalação de laboratórios para fins de pesquisas e treinamentos voltados para a comunidade e sociedade em geral, além de áreas de lazer aprovada através do Projeto de Lei no 4.768/99.

Estas reservas florestais apesar da maioria ser de pequeno porte, não deixam de ter sua importância ecológica no tocante a melhoria do ambiente urbano de Maringá. Todas fazem parte do remanescente da vegetação nativa regional, que se enquadra na região fitogeográfica denominada Floresta Estacional Semidecidual, localizada em parte no Noroeste do Paraná; mas que com o passar dos anos foi perdendo estas características, em função do tipo do solo, cedendo lugar para as culturas agrícolas, ficando sujeitas a enormes ações antrópicas, tais como desmatamento, queimadas, roçadas e aterros; que a transformaram em mata secundária (capoeira e vegetação 
rasteira).

\section{Outros Parques}

Criadas pelo Poder Público, a quem coube definir os seus limites geográficos, devem ser guarnecidos de infraestruturas relacionadas com a questão ambiental, tais como área verde (arborização), área de lazer, lagos e que também poderão ser utilizadas como centro de pesquisa. Neste quesito, a cidade de Maringá conta três parques urbanos: o Parque Gralha Azul, o Parque Alfredo Nyffeler e o Parque das Grevíleas.

\section{a) Parque das Grevíleas}

Este foi um dos primeiros parques criados, localizado na Zona 05 da cidade com uma área de 44.000,00 $\mathrm{m}^{2}$ (PMM/SEPLAN, 1996), foi reflorestado pelo homem com grevíleas (que lhe dá nome), com mudas cedidas pelo viveiro da Companhia Melhoramentos Norte do Paraná (1977). A princípio o local foi projetado para conter três quadras (quarteirões), com datas comerciais e residenciais, porém como o projeto não foi executado, restou somente um grande terreno transformado em parque. Em seu interior, apresenta uma pista de "Cooper" pavimentada, com percurso de 1.050 metros, com diversos aparelhos para ginástica, e frequentada diariamente por centenas de pessoas daquela região.

\section{b) Parque Alfredo Werner Nyffeler}

Localiza-se na Vila Morangueira, zona norte da cidade, com uma área de 164.967,82 m² , cuja criação e construção foi autorizada pela Lei 6.162/88 (PMM/SEPLAN, 1996), lei esta que permitiu a recuperação de um terreno extremamente acidentado (buracão), com processo progressivo de erosão e degradação, utilizado como depósito de lixo e entulhos. Transformado em um ponto turístico da cidade, hoje dotado de boa estrutura para atender os moradores e visitantes, a Prefeitura vem cuidando e prestando serviço de segurança no local, evitando vandalismo e incentivando a participação comunitária. O local possui um excelente lago artificial, formado pelo represamento do 
Córrego Ribeirão Morangueira, tendo também um amplo espaço para atividades esportivas e recreativas, o que proporcionam um excelente espaço para lazer.

\section{c) Parque Gralha Azul}

Este parque foi criado pelo Governo Estadual do Paraná através do programa "Paraná Educação" (SUDERHSA, 1990, 1996), que tinha entre os objetivos a implantação de parques lineares aos cursos d'água, criando áreas verdes, área de lazer e ao mesmo tempo revitalizando fundos de vales. O parque foi implantado em Maringá junto ao Conjunto Ney Braga, com uma área de 19.000,00 m², margeando o Córrego Ribeirão Maringá, cujo local caracteriza-se por ser um fundo de vale e que estava sendo utilizado como depósito de lixo e entulhos diversos prejudicando a qualidade ambiental do córrego. $\mathrm{Na}$ ocasião, foram efetuadas diversas benfeitorias no local, após a desapropriação de uma faixa de terra à margem esquerda do córrego, como o plantio de gramas em toda área, calçadas para caminhadas, iluminação, ciclovia, construção de ponte, anfiteatro e construção de outras infraestruturas de lazer. Entretanto, o parque não está alcançando seus objetivos propostos, pois a frequência da população é baixa, além do descaso do poder público que não adotou nenhuma medida de segurança e proteção para a área; levando a área para uma grande degradação em pouquíssimo tempo.

\section{CONSIDERAÇÕES FINAIS}

Pelo exposto, verificamos a grande importância da criação e instalação de instituições, centros, reservas florestais ou parques ecológicos, com características nativas ou não; mas que mesmo sendo criação do homem, guardam alguns aspectos semelhantes ao ambiente natural (primitivo), tais como a recomposição da vegetação e de lagos artificiais, podendo de alguma forma contribuir para a melhoria na qualidade de vida da comunidade. Do ponto de vista ecológico, as cidades são consideradas grandes centros consumidores dos recursos naturais, pois o oxigênio e a água são consumidos em grandes quantidades, e são eliminados gases tóxicos e restos orgânicos no ambiente (DIAS, 1994); sem contar com a agitação e correria do dia a dia. Estes fatores danosos e estressantes causam sérios danos à saúde humana, e cabe ao homem através do Poder 
Público, efetivar propostas para amenizar os problemas ambientais nos grandes centros urbanos, efetuando um planejamento eficiente para restauração de áreas degradadas através de arborização, reflorestamento, reservando lotes urbanos que poderão ser aproveitados como áreas verdes e outras atividades esportivas e recreativas.

Desde a sua fundação (1947), a cidade de Maringá obedeceu a um plano urbanístico prévio, onde ruas, avenidas, praças, parques e reservas florestais foram antecipadamente projetados e demarcados, revelando uma preocupação ambiental de seus pioneiros. Inicialmente, projetada para ser ocupada por 200.000 habitantes no espaço de 52 anos, Maringá ultrapassou rapidamente esta expectativa inicial, crescimento este o que veio acarretar alguns problemas urbanísticos e ambientais. Diante deste crescimento populacional inesperado, muitos loteamentos foram implantados de maneira a atender as exigências do mercado, deixando excluídas as preocupações ambientais iniciais, o que veio a ocasionar problemas ambientais, tais como desmatamento e a ausência de parques e reservas florestais.

Como a Cidade Canção, Cidade Verde ou Cidade Ecológica, Maringá precisa manter a sua qualidade de vida que Ihe conferiu fama, e que está proporcionando bons dividendos turísticos, como uma das melhores cidades arborizadas do Brasil, inclusive para moradia. Isto somente poderá perpetuar, se forem preservadas as suas reservas florestais e arborização de suas ruas, além da criação de novos ambientes com qualitativos ambientais sustentáveis em seu plano diretor, que proporcionem todo um leque de ambiência com qualidade de vida, entre outros parâmetros como segurança, saúde e educação, etc.

Deve ficar implícito também que, quando o Poder Público cria e instala um parque ou reserva ecológica/florestal em uma determinada área, ele está assumindo oficialmente a proteção desta área; devendo garantir a sua preservação e manutenção, garantindo a sua integridade através de investimentos e fiscalizações, evitando desta forma qualquer ação que possa provocar danos ambientais ao patrimônio.

Sem tecer críticas, mas fazendo uma análise atemporal, embora Maringá seja detentora de inúmeras qualidades conforme citadas ao longo do texto, muitas vezes verificamos que alguns itens ainda deixam a desejar, bastando para isso observar o que ocorre com suas principais reservas florestais, que se encontram abandonadas e necessitam de melhorias urgentes. Como grandes problemas urgentes, podemos citar os 
processos de erosões que existem no Parque do Ingá e Boque II, sem contar com urgentes melhorias que necessitam ocorrer no Horto Florestal. Evidentemente, necessitase também de alguns programas de educação ambiental, para que não ocorram depredações e que a comunidade assumam aquilo que lhes pertencem como maior patrimônio, seu meio ambiente. Um exemplo de descaso público, associado à falta de educação ambiental da sociedade; é onde se encontra o Parque Gralha Azul construído pelo Governo Estadual no qual foi implantada uma série de condições recreativas e ambientais, recuperando a área que funcionava como um verdadeiro lixão, mas hoje se encontra totalmente abandonado, pois devido à falta de um eficiente projeto de consolidação e fiscalização do Poder Público, em pouco tempo de existência o local praticamente foi totalmente abandonado.

Cabe ao Poder Público nos diferentes níveis administrativos, por força de lei ou por força moral e ética, projetar e efetivar um plano de manejo e desenvolvimento de forma adequada e eficiente, com o intuito de evitar a degradação dos principais parques e reservas florestais da cidade, inclusive proporcionando a revitalização das áreas degradadas, para uma melhor qualidade de vida.

\section{REFERÊNCIAS}

BRANCO, Samuel Murgel. Ecologia da cidade, $4^{\mathrm{a}}$ ed. São Paulo: Editora Moderna, 1992, $56 \mathrm{p}$.

Companhia Melhoramentos Norte do Paraná. Colonização e Desenvolvimento do Norte do Paraná, $2^{\mathrm{a}}$ ed. Cinquentenário da Companhia Melhoramentos Norte do Paraná. 1977. 295 p.

DIAS, Genebaldo Freire. Atividades interdisciplinares de educação ambiental. São Paulo: Coedição Global/Gaia. 1994. 112 p.

GARCIA, Júlio César. Maringá Verde? O desafio ambiental da gestão das cidades. Maringá/PR. Eduem - Universidade Estadual de Maringá, 2006.

Governo do Estado do Paraná - Secretaria de Estado de Desenvolvimento Urbano e Meio Ambiente. Coletânea de Legislação Ambiental, Federal e Estadual. 1990. 536 p.

HATSCHBACH, Gert Günther \& ZILTER, Silvia Renate. Lista vermelha de plantas ameaçadas de extinção no Estado do Paraná. Secretária de Estado do Meio Ambiente. Curitiba: Sema, 1995, 139 p. 
Lei Orgânica do Município de Maringá - Estado do Paraná, 1997. vol. único. 154 p.

LOBATO, Carlos Roberto; ANGELIS, Bruno Luiz Domingos de. Áreas verdes públicas urbanas: conceitos, usos e funções. In: Revista Ambiência. v.1, n.1, p. 125-139, 2005.

LUCCI, Elian Alabi. Geografia, o homem no espaço global, $1^{\text {a }}$ ed. São Paulo: Editora Saraiva. 1997. 400 p.

MILANO, Miguel Serediuk. Avaliação quantitativa e manejo de arborização urbana: exemplo de Maringá - PR. 1988. 120p. UFPR (Tese de Doutorado), Curitiba/PR. 1988.

MORAES, Maria Lucia Martins de. Geografia do Brasil - natureza e sociedade. São Paulo: FTD. 1996. 231 p.

Prefeitura Municipal de Maringá - Secretária Municipal do Meio Ambiente e Planejamento. Plano de Manejo Bosque II, vol. único. 1993a. 42 p.

Prefeitura do Município de Maringá - Secretária do Meio Ambiente. Plano de Manejo Parque do Ingá, 1994b. vol. único. 74 p.

Prefeitura Municipal de Maringá - Secretária de Cultura e Turismo. Projeto Memória, 1985.

PAULA, Zuleide Casagrande de. Maringá: o coração verde do Brasil? 1998.

(Dissertação Mestrado em História), Universidade Estadual Paulista - UNESP. Assis/SP. 1998.

Prefeitura Municipal de Maringá - SEPLAN/PMM - Perfil de Maringá. Prefeitura do Município de Maringá - PR, vol. único, 1996, 259 p.

SOUZA, Irridênio Magno Castro de; PALMERIM, Manoel do Socorro dos Santos; CANTUÁRIA, Pablo de Castro. Diagnóstico da arborização de praças públicas do município de Macapá-AP, Brasil. 2006. 66p. Macapá/AP: IMMES (TCC em Engenharia de Florestas Tropicais). 2006.

SUDERHSA - Arquivo do Parque Gralha Azul. Sema, Curitiba-PR, vol. único, 1996.

TUDINI, Odilon Groxiatti. A arborização de acompanhamento viário e a verticalização na zona 7 de Maringá-PR. 2006. 74 p. (Dissertação de Mestrado em Geografia), Universidade Estadual de Maringá, Maringá/SP. 2006.

YOUSSEL, Maria da Penha Bertoldi; HARA, Masao \& RODRIGUES, Rosicler Martins. Atlas dos Ambientes Brasileiros - reservas e ameaças. São Paulo: Editora Scipione. 1997. $130 \mathrm{p}$. 